bold to take the course Hilbert had announced for that term, on the notion of number and the quad. rature of the circle. Most of it went straight over my head. But the doors of a new world swung open for me, and I had not sat long at Hilbert's feet beforo the resolution formed itself in my young heart that I must by all means read and study whatever this man had written. And after the first year I went home with Hilbert's 'Zahlbericht' under my arm, and during the summer vacation I worked my way through it. These were the happiest months of my life, whose shine, across years burdened with our common share of doubt and failure, still comforts my soul." The words "read and study whatever this man had written" are the key to Weyl's breadth and versatility. Hilbert's method of work was to choose a field of mathematics, study it intensely for a few years, revolutionize it with a basic new idea, then drop it and look for another field. Weyl followed the same method, and was equally successful.

The following is a very incomplete chronological summary of Weyl's activity. Between 1908 and 1917 he worked on problems in classical pure mathematics, in particular the theory of numbers, singular integral equations, and functions of a complex variable. His book "Die Idee der Riemannschen Fläche" created a new branch of mathematics by uniting function-theory and geometry; the influence of this book led directly to a synoptic view of analysis, geometry and topology which has become a central theme in the mathematies of to-day. During 1917-23 he worked on the logical foundations of mathematics, and simultaneously took an active part in the development of Einstein's relativity theory and its generalizations. He discovered the first 'unified field theory' in which the Maxwell field appears along with the gravitational field as a geometrical property of spacetime. This theory he soon rejected as being without empirical foundation; but it remains at least as plausible as any of the other unified theories which came later. Between 1923 and 1938 he created a general theory of matrix representations of continuous groups, which powerfully assisted the growth of quantum mechanies. $\mathrm{H}_{\theta}$ discovered that a large proportion of the regularities of quantum phenomena in atomic physics can be understood most simply by means of group theory. By bringing group theory into quantum mechanies he led the way to our modern style of thinking in physies. To-day the instinctive reaction of every theoretical physicist, confronted with an unexplained regularity in the behaviour of elementary particles, is to postulate an underlying symmetry-group.

After taking his degree at Göttingen, Weyl occupied chairs successively at the Federal Technical College in Zurich $(1913-30)$, at Göttingen $(1930-33)$, and at the Institute for Advanced Study in Princeton (1933-51). He was elected a foreign member of the Royal Society in 1936. He was twice married, and is survived by a widow and two sons.

Characteristic of Weyl was an asthetic sense which dominated his thinking on all subjects. He once said to me, half joking, "My work always tried to unite the true with the beantiful; but when I had to choose one or the other, I usually chose the beautiful". This remark sums up his personality perfectly. It shows his profound faith in an ultimate harmony of Nature, in which the laws should inevitably express themselves in a mathematically beautiful form. It shows also his recognition of human frailty, and his humour, which always stopped him short of being pompous. His friends in Princeton will remember him as he was when I last saw him, at the Spring Dance of the Institute for Advanced Study last April : a big jovial man, enjoying himself splendidly, his cheerful face and his light step giving no hint of his sixty-nine years. Frefian J. Dyson

\section{Prof. H. Oertel}

Prof. Horst Oertel, who died on January 9 at the age of eighty-two, was formerly Strathcona professor of pathology in McGill University. Since leaving Canada in 1938, he had lived a retired life at his club in London.

Although born in Germany, near Dresden, Oertel received most of his education in the United States and took his medical degree at Yale in 1894. Shortly afterwards, he returned to Germany for postgraduate studies, first at Berlin, where he was much influenced by Virchow and Senator, and later, at Würzburg and Leipzig. His interest in philosophy, which continued throughout his life, was greatly strengthened by his contact with Wundt, whose reputation as an exponent of physiological psychology was then drawing students and research workers from many parts of the world.

Soon after his return to the United States in 1897, Oertel became the director of a department of pathology-later the Russell Sage Institute-that was then being developed in a large municipal hospital under the auspices of the New York University School of Medicine. In 1911, political changes in the city brought this association to an end, though Oertel maintained for some time longer his connexion with the Russell Sage Foundation. Much of his work at this time was upon nephritis, to the study of which he had been stimulated by Senator, and in 1910 he published a series of lectures on Bright's disease. It was this interest, too, that brought him to London in 1913 to work at Guy's Hospital-near Bright's own wards-on experimental nephritis and the embryology of the kidney. This "delightful and profitable departure", to use his own words, brought him into association with Laidlaw, Boycott, Keith and Assheton. In 1914, while still in London, Oertel received an invitation to an associate professorship at McGill University under J. G. Adami. Almost at once, he assumed full direction of the Department, for Adami left Montreal soon afterwards, first for war service and later to become vice-chancellor of the University of Liverpool.

At McGill, Oertel quickly developed an active pathological institute in close association with the Royal Victoria Hospital, and it was here that his most productive work was done. His previous experience in the United States, Germany and Eng. land had led him to a critical appraisal of the objectives of medical education at a time when the scope of the curriculum was being widened at an unprecedented rate. - His tenure at McGill gave him the opportunity to put some of his views upon teaching into practice. These ideas soon gained a wider audience through the publication in 1921 of his "General Pathology", a book which was followed in 1927 by "Outlines of Pathology" and in 1938 by "Special Pathological Anatomy". All three bear the distinctive marks of Oertel's personality-his absorption with the historical development of pathology and its emergence as an independent biological science. Although addressed to undergraduates, their 
scholarly character can only be properly appreciated by those of wider experience and fuller knowledge of the progressive emancipation of this medical science from its pragmatic origins.

The formative period of Oertel's life was at the time when many young graduates in the United States had come to realize the impact on medicine of the remarkable developments that had taken place during the later nineteenth century in Germany as a result of the mutual fertilization of the medical and fundamental biological ssiences. Although to him a problem in.pathology always appealed as a scientific inquiry that took origin from a wish for a better understanding of causal phenomena in disease, he showed none of that lack of appreciation, not un. known among medical scientists, of the humanitarian demands of medicine. But, like some of the more far-sceing of his contemporaries in his country of adoption, he came early to realize that natural philosophy does not necessarily lose its interest by possessing useful applications, and that efforts to solve the problems presented by disease are not necessarily without intellectual attraction. It was the effort to combine the searchings of the philosopher with the responsibility of the physician that distinguished Oertel's contributions to pathology.

G. Payling Wright

\section{Mr. Sidney G. Starling}

Sidney G. Starling died on December 16, at the age of eighty-two. He was born in Bradford and received his early education at the Grammar School and Technical College. Having obtained an exhibition and national scholarship, he entered the Royal College of Science, London, in 1891 under Prof. Rücker. Here he secured first-class honours, prizes and medals and worked as assistant and demonstrator during 1893-95. Working under C. V. Boys, he undertook the calculations required for the determination of the Newtonian constant of gravitation. Between 1895 and 1898 he was assistant lecturer in mathematics and physics at Battersea Polytechnic, during which time he graduated at the University of London and was awarded the Neil Arnott Exhibition and Medal. At the opening of the West Ham Iechnical Institute in 1898, he was appointed the first head of the Department of Physics and Mathematics, a post he held until his retirement in 1932. In 1899 he married Miss M. Briggs, who was an assistant in the Art Department at Battersea.

Throughout his lifetime, he was an active member of the Board of Studies in Physics in the University of London and a member of the Faculty of Science. In his earlier years he was an extensive abstractor of Continental papers for the Institution of Electrical Engineers and the Physical Society of London. In 1920 he was elected Fellow of the Institute of Physies.

Starling is probably most widely known as a writer of text-books of physics. The association of Duncap (the engineer) with Starling (the physicist) in the production of their "Text Book of Physics" (1918) was suggested by Sir Richard Gregory, of whem Starling was a great friend. Starling's own "Electricity and Magnetism for Advanced Students" (1912) has been a standard text-book throughout the yoars, appearing in many editions, the latest being rovised in collaboration with A. J. Woodall in 1953. During his retirement there have appeared "Mechanical Properties of Matter" (1935), "Physics" (in col- laboration with A. J. Woodall, 1950) and a revision of "Science in the Service of Man-Electricity" (in association with his son-in-law, H. J. Gray, 1949).

Staff and students respected Starling for his sympathetic understanding, scientific integrity and the quiet efficient way he solved technical and organization problems. There was not the slightest procrastination or duplication of effort. He was a strict disciplinarian and a stickler for punctuality. The ease with which he could erect apparatus for research or demonstration was particularly noteworthy. His published researches and writings do not convey his skill and versatility in this direction. In particular, he did pioneer work on aeroplane compasses (theoretical and experimental) at the time of the First World War.

All his hobbies were characterized by high achievement with apparently little exertion, ranging from shooting, golf and photography to silver smithing. From 1912 he had taken a very active part in Freemasonry. Only his closest friends will have appreciated his keen sense of humour, and even they can scarcely realize the many kindly acts of sympathy and encouragement he rendered to those in adversity. $\mathrm{He}$ is survived by a son and daughter.

WiLIIAM SWaINe

\section{Dr. George Slater}

Dr. George Stater, one of the leading glaciologists of Great Britain, died at the age of eighty-one on January 27. He started his geological career when a schoolboy at St. John's College, York. Later, he continued as an amateur geologist while a schoolmaster at Haltwhistle, Northumberland (1895-97), and at Ipswich (1897-1918). He showed an early interest in palæontology, but at Ipswich, to quote Dr. F. A. Bather, he "became entangled with the complicated drifts of Suffolk". Patiently he mapped and recorded the structures seen in these disturbed drifts, in temporary sections, on successive faces in sand-pits and, during the First World War, in trenches dug for Army training. Though he published little during this early period, he became recognized as an authority on the glacial drifts of East Anglia, and in 1907 and 1911 led field excursions of the Geologists' Association at Ipswich.

He entered the Imperial College (Royal College of Science) in 1918 and remained a member of the geological staff until his retirement in 1939, having obtained the degree of D.Sc. (London) in 1926. The Geological Society awarded him the Murchison Fund in 1928, and in 1950 he received the Foulerton Award 'of the Geologists' Association.

Slater's research work was predominantly concerned with glaciology; and in 1921, when he accompanied the Oxford University Expedition to Spitsbergen as glaciologist, he was able to compare the structures seen in living glaciers with those that he had observed in the drift deposits of East Anglia. The results of his Spitsbergen work were published in the Journal of Geology (33, 4.08; 1925), and the next year he enunciated his ideas on "Glacial Tectonics as reflected in Disturbed Drift Deposits" (Proc. Geol. Assoc., 37, 392 ; 1926). Between 1925 and 1932, at least fourteen papers dealing with various aspects of this theory were published. In them he described, often in meticulous detail, the structures seen in disturbed drifts and in glaciers. $\mathrm{His}$ theory that these drift structures were actually 